\title{
Pyrocatechol Violet Modified Graphite Pencil Electrode for Flow Injection Amperometric Determination of Sulfide
}

\author{
Gamze Emir*, Serkan Karakaya, and Yusuf Dilgin \\ Canakkale Onsekiz Mart University, Science and Arts Faculty of Department of Chemistry, 17100-Çanakkale, Turkey
}

\begin{abstract}
In this study, pyrocatechol violet (Pcv) is proposed for the first time as an efficient electrocatalyst for oxidation of sulfide and flow injection analysis (FIA) of sulfide. A graphite pencil electrode (GPE) was modified with Pcv via immersion of the GPE into $0.01 \mathrm{M}$ Pcv solution for $15 \mathrm{~min}$. Cyclic voltammograms (CVs) demonstrated that Pcv/GPE exhibits a good electrocatalytic performance due to shift in the potential from +400 at bare GPE to $+70 \mathrm{mV}$ at Pcv/GPE and obtaining an enhancement in the peak current compared with the bare GPE. A linear range between 0.25 and $250 \mu \mathrm{M}$ sulfide with a detection limit of $0.07 \mu \mathrm{M}$ was obtained from the recorded current-time curves in Flow Injection Analysis (FIA) of sulfide. Sulfide in water samples was also successfully determined using the proposed FI amperometric methods.
\end{abstract}

Keywords : Graphite Pencil Electrode, Pyrocatechol Violet, Electrocatalytic Oxidation, Sulfide, Flow Injection Analysis Received : 31 October 2019, Accepted : 14 January 2020

\section{Introduction}

Sulfur $\left(\mathrm{S}^{2-}\right)$, the reduced form of sulfur compounds (such as $\mathrm{HS}^{-}$and $\mathrm{H}_{2} \mathrm{~S}$ ), is generally formed in waste water by anaerobic bacteria on organic matter [1]. It has been reported that over 50 ppm of sulfide concentration was declared as to be high toxicity which is harmful to the human health [2]. Beside toxic effects, the studies in the last decade approved that $\mathrm{H}_{2} \mathrm{~S}$ acts a significant role in extending of the postharvest shelf life of many herbal foods such as vegetables and fruits $[2,3,4]$. Also, sulfide salts have been commonly used to control the toxic metal levels in environment, because most of metal sulfides are insoluble and they are easily found as precipitated in waste waters [1]. Due to the mentioned reasons above, detection of sulfide has aroused significant interest on the analytical researchers [1]. Therefore, selective, rapid and sensitive determination of sulfide has aroused a massive significance and interest for scientists [2].

Pyrocatechol violet (Pcv), 1,2-Benzenediol, 4,4'-

*E-mail address: gemir@stu.comu.edu.tr

DOI: https://doi.org/10.33961/jecst.2019.00605

This is an open-access article distributed under the terms of the Creative Commons Attribution Non-Commercial License (http://creativecommons.org/licenses/by-nc/4.0) Attribution Non-Commercial License (http://creativecommons.org/licenses/by-nc/4.0)
which permits unrestricted non-commercial use, distribution, and reproduction in any which permits unrestricted non-commercial use, distri
medium, provided the original work is properly cited.
(3H-2,1-benzoxathiol-3-ylidene)bis-, S,S-dioxide; is an aromatic sulfonic acid dye synthesized from the condensation reaction between pyrocatechol and osulfobenzoic acid anhydride in the mole ratio of 2:1 [5]. Pcv has been widely used as a colorimetric and efficient complexometric reagent as well as an indicator in various analytical studies because it forms stable colored complexes with various metal ions [59]. Pcv can be strongly adsorbed onto inorganic materials due to containing catechol groups which have $-\mathrm{OH}$ groups bonding to the adjacent carbon atoms of the aromatic ring; furthermore, it has conjugated $\pi-\pi$ bonds $[9,10]$. In addition, Pcv can be polymerized on electrode surfaces so that obtained polymeric films of Pcv possess a larger surface area, more active sites, better conductivity, etc. in comparison with a modified electrode prepared in its monomeric form [9-13]. Therefore, Pcv has been used as an efficient redox mediator for electrocatalytic oxidation of several biologically and environmentally important compounds and also for the sensitive and selective determination of metal ions [9-23]. For example, the electrocatalytic oxidation of NADH [9,13], hydrazine [10-12] and $\mathrm{H}_{2} \mathrm{O}_{2}$ [10,17-19], construction of ethanol biosensor [9], and the simultaneous determination of uric acid, xanthine and hypoxanthine [12] have been reported using Pcv- 
modified electrodes. Moreover, voltammetric determination of $\mathrm{Cd}$ and $\mathrm{Pb}$ [11], $\mathrm{Cu}$ species [20] and $\mathrm{Al}$ [21] was successfully achieved at various types of Pcv-modified electrodes.

Chemically-modified electrodes (CMEs) prepared with organic redox mediators have been extensively used in the determination of various compounds based on their electrocatalytic oxidation or reduction at CMEs. One of the applications of the CME is determination of sulfide based on the electrocatalytic oxidation of sulfide at the CME. Oxidation of sulfide at bare electrodes has some drawbacks, such as a highly-irreversible and broad oxidation peak with overpotential, poor selectivity and unstable and weak analytical signals resulting in low sensitivity due to adsorption of oxidation products of the sulfide onto the electrode surface. In order to overcome these problems, various organic redox mediators such as hematoxylin, quercetin, calmagite, methylene blue, alizarin, hemin, ferricyanide, etc. have been used for the electrocatalytic oxidation of sulfide [22-34]. It can be said that amperometric [23-31], voltammetric [32-34] and potentiometric methods [35] have been successfully developed for the electrochemical determination of sulfide. However, our search of the literature shows that Pcv used as an efficient electrocatalyst for many compounds has so far not been used for the electrocatalytic oxidation of sulfide.

In this study, Pcv was modified onto the GPE by the adsorption and flow injection analysis (FIA) of sulfide is proposed based on its electrocatalytic oxidation at the Pcv/GPE, for the first time. Recently, the GPE has attracted a great deal of attention as a working electrode in electroanalytical studies since it possesses important properties, such as high electrochemical reactivity, ease of surface modification, high stability, low cost, disposable electrode material, and avoidance of time-consuming polishing procedures [9,2325,36-45]. Thus the combination of an advantageous electrode (GPE) and the electrocatalytic property of redox mediator $(\mathrm{Pcv})$ offer a selective, sensitive and cheap FI amperometric sulfide sensor.

\section{Experimental}

\subsection{Chemicals, Reagents and Apparatus}

All the chemicals used in this study are in analytical grade. Pcv, sodium sulfide nonahydrate $\left(\mathrm{Na}_{2} \mathrm{~S} .9 \mathrm{H}_{2} \mathrm{O}\right)$ and cysteamine hydrochloride were purchased from Sigma-Aldrich. L-ascorbic acid, uric acid, sitric acid, salicylic acid, L-glutamic acid, Dglucose, $\mathrm{K}_{3}\left[\mathrm{Fe}(\mathrm{CN})_{6}\right], \mathrm{K}_{4}\left[\mathrm{Fe}(\mathrm{CN})_{6}\right] \cdot 3 \cdot \mathrm{H}_{2} \mathrm{O}, \mathrm{NaOH}$, $\mathrm{CH}_{3} \mathrm{COOH}, \mathrm{H}_{3} \mathrm{BO}_{3}, \mathrm{H}_{3} \mathrm{PO}_{4}$ and $\mathrm{KCl}$ were supplied from Merck Company. Dopamine hydrochloride was bought from Alfa-Easer.

The stock solutions of $0.10 \mathrm{M}$ sodium sulfide nonahydrate and $0.01 \mathrm{M} \mathrm{Pcv}$ were prepared in deoxygenated $10 \mathrm{~mL}$ of $0.10 \mathrm{M} \mathrm{NaOH}$ and in $5 \mathrm{~mL}$ of deoxygenated ultrapure water, respectively. The stock $\mathrm{Na}_{2} \mathrm{~S}$ solution was daily prepared and standardized by the iodometric method. Standard $\mathrm{Na}_{2} \mathrm{~S}$ solutions were prepared by dilution of standardized stock solution $\left(0.10 \mathrm{M} \mathrm{Na}_{2} \mathrm{~S}\right)$ in deoxygenated $\mathrm{pH}$ 9.0 Britton Robinson buffer solution (BRBS). The BRBS was prepared by mixing the appropriate volumes of acid solution (including $0.040 \mathrm{M} \mathrm{H}_{3} \mathrm{PO}_{4}$, $0.040 \mathrm{CH}_{3} \mathrm{COOH}, 0.040 \mathrm{H}_{3} \mathrm{BO}_{3}, 0.10$ or $1.0 \mathrm{M} \mathrm{KCl}$ ) and alkaline solution (including $0.20 \mathrm{M} \mathrm{NaOH}, 0.10$ $\mathrm{M}$ or $1.0 \mathrm{M} \mathrm{KCl})$ and the $\mathrm{pH}(9.0)$ of buffer solution was arranged by a Hanna HI $221 \mathrm{pH}$-meter with combined glass electrode. Ultrapure water from Elga Option Q7B water purification system (18.2 $\mathrm{M} \Omega \mathrm{cm}$ ) was used in preparation of the all solutions.

The traditional three-electrode system consisting of Pt wire, $\mathrm{Ag} / \mathrm{AgCl}_{(\mathrm{sat} . \mathrm{KCl})}$ and graphite pencil electrode (GPE) was used in the electrochemical experiments. GPEs supplied from Tombow 2B (diameter: $0.5 \mathrm{~mm}$, length: $10 \mathrm{~cm}$ ) was placed into holder and a geometric area of $0.159 \mathrm{~cm}^{2}$ (total length: $1.0 \mathrm{~cm}$ ) was used in all electrochemical experiments. Electrochemical measurements were carried out using devices reported in our previous study [14].

\subsection{Experiments on Electrocatalytic Oxidation at Modified Electrode}

A procedure in a previously published article was partially modified and used for the modification of Pcv onto GPE surface in this study [14]. Differently from this published procedure, GPE was immersed in the solution of $0.01 \mathrm{M} \mathrm{Pcv}$ stock solution for $15 \mathrm{~min}$, washed with ultra-pure water and dried at room temperature before use. To show the electrocatalytic oxidation of sulfide at the Pcv/GPE, CVs of bare GPE and Pcv/GPE were recorded in the absence and presence of $0.20 \mathrm{mM}$ sulfide at the $\mathrm{pH} 9.0$ BRBS with $0.10 \mathrm{M} \mathrm{KCl}$ in the potential range between $-0.30 \mathrm{~V}$ and $+0.60 \mathrm{~V}$ at a scan rate of $50 \mathrm{mV} \mathrm{s}^{-1}$. 


\subsection{Flow Injection Analysis of Sulfide at Pcv/GPE}

A home-made electrochemical flow cell proposed in our previous studies [40-42] was also used for the FIA of sulfide at the Pcv/GPE. The FIA of sulfide was performed by recording current time curves at a constant potential using a carrier solution of $\mathrm{pH} 9.0$ BRBS with $1.0 \mathrm{M} \mathrm{KCl}$. In this context, the optimum working potential and flow rate values were determined by injection of $1.0 \times 10^{-4} \mathrm{M}$ sulfide into the FIA system. To determine the analytical performance parameters (linearity range, limit of detection, reproducibility, selectivity) of the FI amperometric sulfide sensor, sulfide solutions prepared at different concentrations, carrier solution as a blank, a sulfide solution with a known concentration and sulfide solutions including possible interference compounds were individually injected into the FIA system. For each experiment, FI amperometric current time curves (Fiagrams) were recorded under optimized conditions.

In the final step, the proposed sensor was applied to determine sulfide in the water samples. For this, two water samples (sea water from the Dardanelles Straits and tap water obtained from the municipality of Çanakkale, Turkey) were used. FI amperometric responses of the Pcv/GPE were monitored by injection of these water samples into the FIA system under optimized conditions after the water samples had been spiked with sulfide in BRBS including $1.0 \mathrm{M} \mathrm{KCl}$.

\section{Results and Discussion}

\subsection{Electrochemical Characterization and Behav- ior of Pcv/GPE}

In our previous report [14] studies on the electrochemical characterization with electrochemical impedance spectra (EIS) and electrochemical behavior of Pcv modified GPE with CVs was performed as detail. The reported EIS showed that transfer resistance $\left(R_{c t}\right)$ values of $200 \Omega$ for obtained the bare GPE increased to $250 \Omega$ by adsorption of GPE with Pcv. The rather high $R_{c t}$ value of the modified electrode explained by formation of negatively charged sulfonic acid group in the Pcv which repel the anionic redox probes $\left(\left[\mathrm{Fe}(\mathrm{CN})_{6}\right]^{3-/ 4-}\right)$ diffused to electrode surface. This electrostatic repulsion obstructs electron transfer between redox probe and electrode and therefore $\mathrm{R}_{\mathrm{ct}}$ values of the bare GPE slightly increased by adsorp- tion of Pcv onto the electrode surface. These results indicate that the modification of Pcv on the GPE was achieved via adsorption procedure. In addition, reported CVs showed that the anodic and cathodic peak currents of Pcv/GPE increased linearly based on scan rate indicates an adsorption-controlled process taking place in the solution [14]. Moreover, it was reported that the all peak potentials of Pcv changed depending on $\mathrm{pH}$ between $\mathrm{pH} 2$ and 10 [14].

\subsection{Electrocatalytic Oxidation of Sulfide at Pcv/ GPE}

Fig. 1 shows CVs of $0.2 \mathrm{mM}$ sulfide in $\mathrm{pH} 9.0$ BRBS with $0.1 \mathrm{M} \mathrm{KCl}$ at the bare GPE and Pcv/ GPE. While bare GPE has not any peak in its baseline CV (Fig. 1a), oxidation of sulfide at bare GPE started at $+100 \mathrm{mV}$ and turned into a broad and irreversible oxidation peak located at $+400 \mathrm{mV}$ (Fig. 1b). On the other hand, two redox couples located at anodic $(-20 \mathrm{mV}$ and $+100 \mathrm{mV})$ and cathodic $(-60 \mathrm{mV}$ and $+75 \mathrm{mV})$ directions attributed to reversible oxidation of the catechol groups to quinone were obtained from the CVs of the Pcv/GPE in the absence of sulfide (Fig. 1c). Upon the addition of $0.20 \mathrm{mM}$ $\mathrm{Na}_{2} \mathrm{~S}$, a sharp enhancement in current at these anodic peaks was observed at the potential of $+70 \mathrm{mV}$. Simultaneously, the cathodic peak that located at $+75 \mathrm{mV}$ disappeared and the current of the other cathodic peak located at $-60 \mathrm{mV}$ decreased (Fig. 1d). In general, decrease in overpotential and enhance-

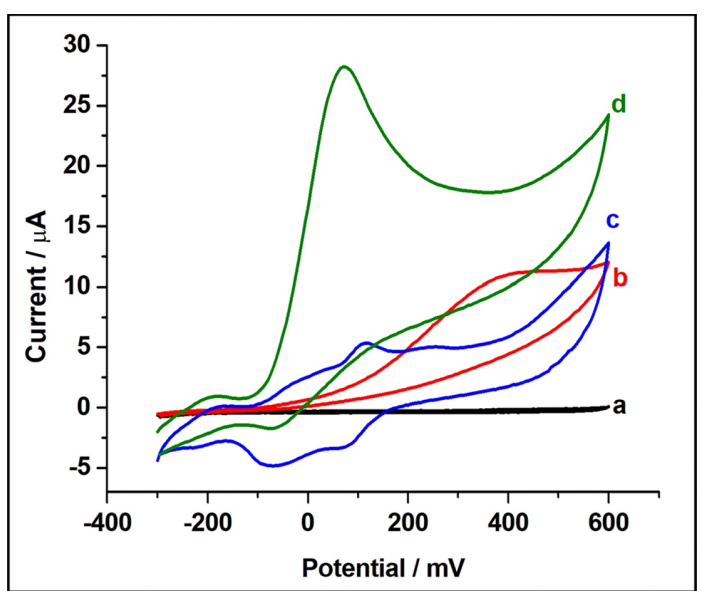

Fig. 1. CVs of bare GPE (a and b) and Pcv/GPE (c and d) in absence (a and c) and presence (b and d) of $0.20 \mathrm{mM}$ $\mathrm{Na}_{2} \mathrm{~S}$ in pH 9.0 BRBS with $0.10 \mathrm{M} \mathrm{KCl}$ at $50 \mathrm{mV} \mathrm{s}^{-1}$. 


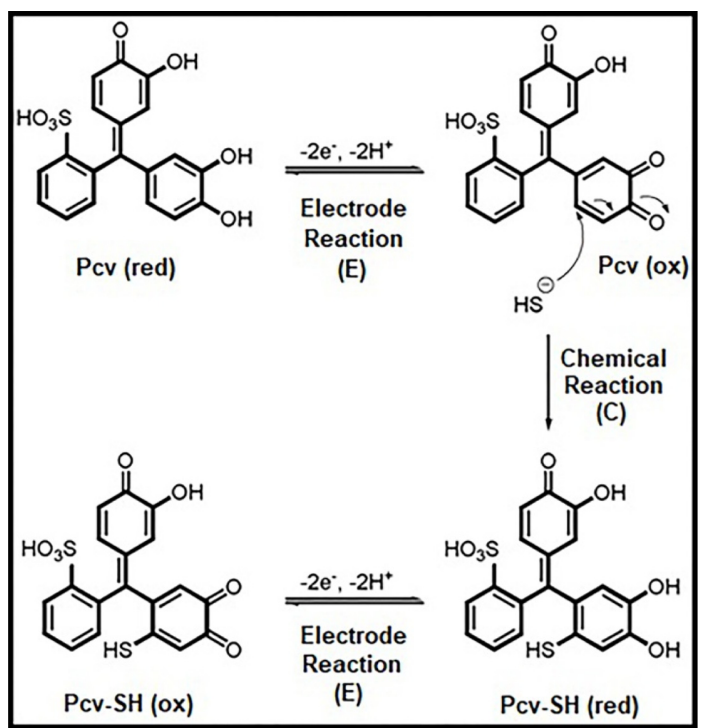

Scheme 1. Schematic representation of preparation of modified electrodes and proposed mechanism for electrocatalytic oxidation of sulfide at Pcv/GPE.

ment in catalytic current are both significant parameters in consideration of electro catalytic effect. The obtained results showed that Pcv/GPE exhibits a favorable electro catalytic effect towards the oxidation of sulfide. Similar electrocatalytic activity of Pcv-modified electrodes was also reported for other compounds such as NADH $[9,13]$, hydrazine [14-16] and $\mathrm{H}_{2} \mathrm{O}_{2}$ [10,17-19].

An Electrochemical-Chemical-Electrochemical (ECE) mechanism proposed for electrocatalytic oxidation of sulfide at organic redox mediators with modified electrodes in previous studies can also be proposed for the Pcv/GPE [23-25]. Scheme 1 shows the electrocatalytic oxidation mechanism of sulfide at the Pcv/GPE. In the first step, Pcv on the GPE surface is oxidized by reversible redox reaction of the catechol groups, which convert to quinone in the structure of Pcv. A large part of the sulfide exists in $\mathrm{HS}^{-}$form in the $\mathrm{pH}$ 9.0 BRBS and the $\mathrm{HS}^{-}$acts as a nucleophilic agent for a Michael addition-reduction reaction. Thus, this reaction takes place between the oxidized form of Pcv and $\mathrm{HS}^{-}$and a reduced adduct compound forms at the end of this reaction in the second step. In the last step, thiol moiety in the structure of the product facilitates re-oxidation of the additional product due to its electron-donating property and the formed reduced compound (catechol groups) is further electrochemically reoxidized to quinone groups, so the anodic peak current of the mediator increases in the presence of sulfide. After formation of the adduct compound, the electrocatalysis proceeds through a chemical reaction between the oxidized form of the adduct compound (Pcv-SH(ox)) and sulfide. Pcv-SH(ox) is reduced to Pcv-SH(red), while the sulfide is oxidized to $\mathrm{SO}_{3}{ }^{2-}$ (Scheme 1). In the final step, Pcv-SH(red) is reoxidized by giving its electrons to the electrode.

\subsection{Amperometric Determination of Sulfide at Pcv/GPE in FIA system}

Before starting to the FIA of sulfide using proposed electrode, two parameters (working potential and flow rate) which affect the peak current were optimized. The fiagrams of $1.0 \times 10^{-4} \mathrm{M}$ sulfide were recorded at bare GPE and the Pcv/GPE at various working potentials. The plot of peak currents versus working potential for both electrodes shown in Fig. 2A illustrates that the response of the Pcv/GPE toward sulfide is better than the bare GPE and that the sulfide oxidized at a more negative working potential due to electrocatalytic activity of the Pcv/ GPE. For the following studies, a working potential of $+100 \mathrm{mV}$ was selected as optimum working potential because, electrocatalytic currents of $1.0 \times 10^{-4} \mathrm{M}$ sulfide at $+100 \mathrm{mV}$ at the Pcv/GPE were fifty times higher than its oxidation current at the GPE. The fiagrams of $1.0 \times 10^{-4} \mathrm{M}$ sulfide at the Pcv/GPE at $+100 \mathrm{mV}$ were recorded at various flow rates. It can be seen that the peak currents heightened by increasing the flow rate until $2.0 \mathrm{~mL} \mathrm{~min}^{-1}$ then decreased after this point. As can be seen inset in Fig. 2B, the maximum current was obtained at a flow rate of $2.0 \mathrm{~mL} \mathrm{~min}^{-1}$. Therefore, this value was used as optimum flow rate for the following studies.

Fig. 3A and 3B show fiagrams of various concentrations of sulfide recorded at the bare GPE and Pcv/ GPE, respectively, in the carrier stream of the $\mathrm{pH} 9.0$ BRBS including $1.0 \mathrm{M} \mathrm{KCl}$ under optimized conditions (working potential of $+100 \mathrm{mV}$ and a flow rate of $\left.2.0 \mathrm{~mL} \mathrm{~min}^{-1}\right)$. Peak currents increased in accordance with an increase of sulfide concentration for both electrodes; however, peak currents obtained from the Pcv/GPE were found to be significantly higher compared with the bare GPE for all concentrations. The plots of peak current versus sulfide con- 


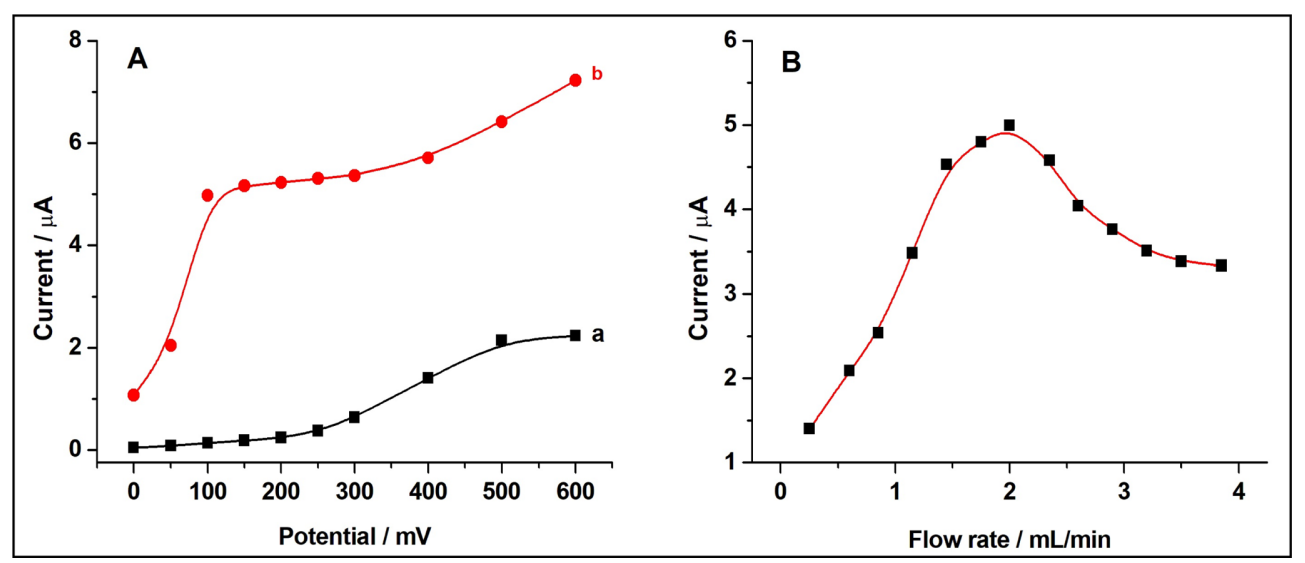

Fig. 2. A) Graph of electrocatalytic current of sulfide $(0.10 \mathrm{mM})$ versus working potential for bare GPE (a) and Pcv/GPE (b) and B) Graph of electrocatalytic current of sulfide $(0.10 \mathrm{mM})$ versus flow rate.

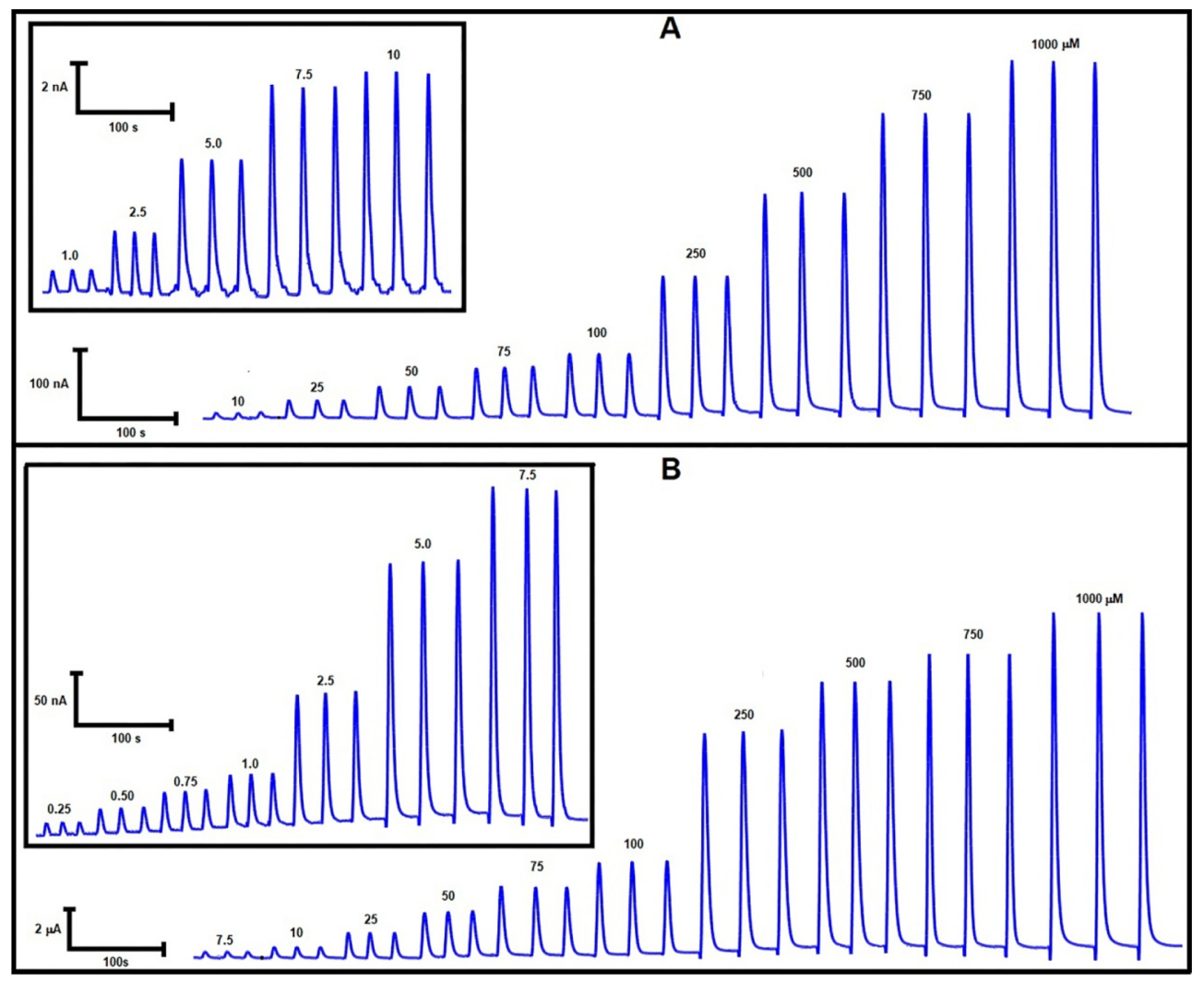

Fig. 3. Fiagrams of A) bare GPE and $\mathrm{B}$ ) Pcv/GPE according to increased sulfide concentration in Ar-saturated $\mathrm{pH} 9.0$ BRBS with $1.0 \mathrm{M} \mathrm{KCl}$ at $100 \mathrm{mV}$ and $2.0 \mathrm{~mL} \mathrm{~min}^{-1}$.

centration and obtained calibration curves are shown in Figs. 4A and 4B for the bare GPE and Pcv/GPE, respectively. As displayed in the inset of Fig. $4 \mathrm{~A}$, peak currents of sulfide at the bare GPE increased linearly depending on sulfide concentration ranging from 1.0 to $250 \mu \mathrm{M}$ with a linear equation of $\mathrm{I}(\mu \mathrm{A})=$ 


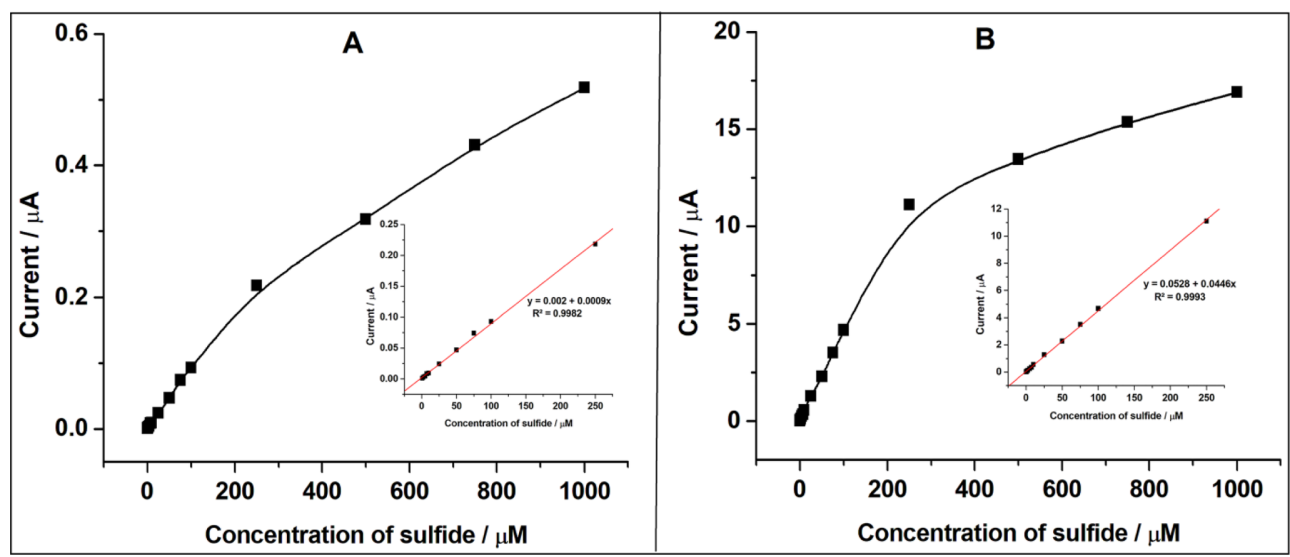

Fig. 4. Graph of current versus sulfide concentration for A) bare GPE and B) Pcv/GPE (Inset: Calibration curves between current and concentration of $\mathrm{Na}_{2} \mathrm{~S}$ for each electrode).

Table 1. Comparison of merits of the Pcv/GPE with other modified electrodes prepared using redox mediators in previous studies.

\begin{tabular}{|c|c|c|c|}
\hline Modified Electrode & Detection Potential $(\mathrm{mV})$ & nearity range $(\mu \mathrm{M})$ & $\operatorname{LOD}(\mu \mathrm{M})$ \\
\hline Hematoxylin modified GPE [23] & +200 vs. $\mathrm{Ag} / \mathrm{AgCl}$ & $1-200$ & 0.4 \\
\hline Quercetin modified GPE [24] & +300 vs. $\mathrm{Ag} / \mathrm{AgCl}$ & $1-20 \& 20-800$ & 0.3 \\
\hline Poly-calmagite modified GPE [25] & +300 vs. $\mathrm{Ag} / \mathrm{AgCl}$ & $0.1-500$ & 0.03 \\
\hline Hematoxylin-MWCNT modified Carbon paste electrode [26] & $+150 \mathrm{mV}$ vs. $\mathrm{Ag} / \mathrm{AgCl}$ & $0.5-150$ & 0.2 \\
\hline Poly-methylene blue modified GCE [28] & +150 vs. $\mathrm{Ag} / \mathrm{AgCl}$ & $0.5-500$ & $\begin{array}{l}0.27 \\
0.15\end{array}$ \\
\hline $\begin{array}{l}\text { GCE modified with a cellulose acetate polymeric film bearing } \\
\text { 2,6-dichlorophenolindophenol [27] }\end{array}$ & +80 vs. $\mathrm{Ag} / \mathrm{AgCl} /$ & $20-1000$ & 17 \\
\hline Hemin functionalized reduced grapheme oxide modified GCE [28] & +50 vs. $\mathrm{Ag} / \mathrm{AgCl}$ & $2-212$ & 1.3 \\
\hline $\begin{array}{l}\text { Ferricyanide polymeric ionic liquid modified Screen printed carbon } \\
\text { paste electrode [29] }\end{array}$ & 0.0 vs. $\mathrm{Ag} / \mathrm{AgCl}$ & $1-3000$ & 0.0129 \\
\hline $\begin{array}{l}\text { Screen printed Pt electrode modified with 2-(4-fluorophenyl) } \\
\text { indole-modified xerogel [31] }\end{array}$ & +450 vs. $\mathrm{Ag} / \mathrm{AgCl}$ & $10-2000$ & 6 \\
\hline Alizarin and reduced graphene oxide nanosheets modified GCE [33] & +465 vs. $\mathrm{Ag} / \mathrm{AgCl}$ & $6-3280$ & 1 \\
\hline Pcv modified GPE (This work) & +100 vs. $\mathrm{Ag} / \mathrm{AgCl}$ & $0.25-250$ & 0.07 \\
\hline
\end{tabular}

$0.0009 \mathrm{C}(\mu \mathrm{M})+0.002\left(\mathrm{R}^{2}=0.9982\right)$. However, peak currents of sulfide obtained from fiagrams of the Pcv/GPE increased linearly between 0.25 and 250 $\mu \mathrm{M}$ sulfide concentration, with a linear equation of I $(\mu \mathrm{A})=0.0446 \mathrm{C}(\mu \mathrm{M})+0.0528\left(\mathrm{R}^{2}=0.9993\right)$, as shown in Fig. 4B inset. In addition, the limit of detection (LOD) was found to be $0.07 \mu \mathrm{M}$ based on $3 \times \mathrm{S}_{\text {blank }} /$ slope. Slope of calibration curves for both electrodes show that the FI amperometric response of the Pcv/GPE is about 50 times higher than the bare GPE due to the higher sensitivity and efficient electrocatalytic activity of the Pcv/GPE toward oxidation of sulfide.

To discuss the advantages of the proposed method for electrocatalytic determination of sulfide, results of the Pcv/GPE experiment were compared with previous studies in which various organic redox mediator-modified electrodes were used. As seen in Table 1, the LOD of the Pcv/GPE is lower than that of other organic redox mediator-modified electrodes, indicat- 


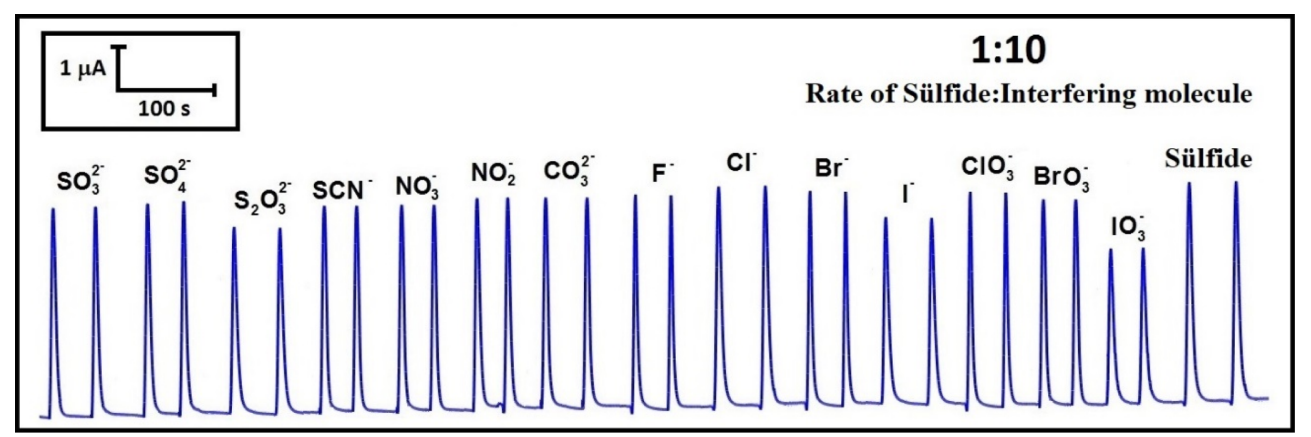

Fig. 5. The fiagrams of Pcv/PGE recorded by injections of solutions 1:10 ratios including sulfide and interfering molecules. (Carrier solution: Ar-saturated pH 9.0 BRBS with $1.0 \mathrm{M} \mathrm{KCl}$ at $100 \mathrm{mV}$ and $2.0 \mathrm{~mL} \mathrm{~min}^{-1}$ )

ing that the proposed electrode has good sensitivity. Moreover, FI amperometric detection of sulfide at the Pcv/GPE was carried out at $+100 \mathrm{mV}$, which is a more negative value than the detection potential of some modified electrodes given in Table 1. On the other hand, those redox mediators were generally modified on expensive electrodes with low reproducibility and involving time-consuming polishing steps compared to the GPE. Although hematoxylin [23] quercetin [24] and calmagite [25] modified GPEs were used for electrocatalytic oxidation of sulfide in our previous studies, FI amperometric determination of sulfide was studied only at a calmagite-modified GPE. It is generally known that interference effects of some biologically important molecules (such as dopamine, ascorbic acid and uric acid etc.) are intensive at high potentials. However, the Pcv/GPE exhibits significant sensitivity for the detection of sulfide at lower detection potential $(+100 \mathrm{mV})$ compared to the calmagite-modified GPE (+250 mV). As a result, (i) Pcv, (ii) GPE and (iii) FIA system were firstly combined for sensitive FI amperometric determination of sulfide.

\subsection{Interference Effect of Compounds on FI Amperometric Detection of Sulfide}

Fiagrams of sulfide at the Pcv/GPE were recorded in the presence of some anions $\left(\mathrm{SO}_{3}{ }^{2}, \mathrm{SO}_{4}{ }^{2-}, \mathrm{S}_{2} \mathrm{O}_{3}{ }^{2-}\right.$, $\mathrm{SCN}^{-}, \mathrm{NO}_{2}{ }^{-}, \mathrm{NO}_{3}{ }^{-}, \mathrm{CO}_{3}{ }^{2-}, \mathrm{Cl}^{-}, \mathrm{F}^{-}, \mathrm{Br}^{-}, \mathrm{I}^{-}, \mathrm{ClO}_{3}{ }^{-}, \mathrm{BrO}_{3}{ }^{-}$, $\left.\mathrm{IO}_{3}{ }^{-}\right)$and these result shows that in Fig. 5. The FI amperometric curve recorded by injections of solutions including varying ratios of sulfide:interfering molecules which are 1:1, 1:2, 1:5 1:10. Also some compounds such as hydrazine, hydrogen peroxide, ascorbic acid (AA), uric acid (UA) and dopamine
(DA), which are usually found in environmental and biological samples were used for interference studies. An error rate of less than $10 \%$ was taken into consideration for the interference effect of substances on the determination of $1.0 \times 10^{-4} \mathrm{M}$ sulfide at different interference ratios $(1: 1,1: 2,1: 5$ and 1:10). Results of these interference experiments demonstrated that all studied anions except for $\mathrm{IO}_{3}{ }^{-}$do not exhibit any interference effect on sulfide. However, some compounds such as hydrazine, AA, UA and DA had a considerable impact, whereby the peak current of the sulfide increased significantly in the presence of these compounds. However, their interference cannot be considered as significant due to the rare presence of these compounds in environmental samples.

\subsection{Determination of Sulfide in Water Samples with Proposed Electrode}

Two water samples were used for investigation of the applicability of the proposed method in real samples; sea water from the Dardanelles Straits and tap water obtained from the municipality of Çanakkale, Turkey. FI amperometric responses of the Pcv/GPE were monitored by injection of the water samples into the FIA system under optimized conditions after the water samples had been spiked with sulfide in BRBS including 1.0 M KCl. The obtained results (Table 3) demonstrated that the proposed electrode has good recovery in the range of 98.4 to $104.4 \%$ for determination of sulfide. It can be concluded that a practical, fast and cheap FI amperometric method for sulfide detection in water samples was successfully developed using an efficient redox mediator (Pcv) modified GPE. 
Table 2. Recovery values of sulfide added to real water samples $(n=5)$.

\begin{tabular}{cccc}
\hline \hline Sample & Added $\left(\mathrm{mol} \mathrm{L} \mathrm{L}^{-1}\right)$ & Found $\left(\mathrm{mol} \mathrm{L}^{-1}\right)$ & Recovery $(\%)$ \\
\hline \multirow{2}{*}{ Tap water } & $1.0 \times 10^{-6}$ & $9.89 \times 10^{-7} \pm 4.5 \times 10^{-8}$ & 98.9 \\
& $1.0 \times 10^{-5}$ & $1.02 \times 10^{-5} \pm 2.3 \times 10^{-7}$ & 102.0 \\
& $7.5 \times 10^{-5}$ & $7.58 \times 10^{-5} \pm 9.3 \times 10^{-7}$ & 91.2 \\
& $1.0 \times 10^{-4}$ & $9.99 \times 10^{-5} \pm 2.8 \times 10^{-6}$ & 99.9 \\
& $2.5 \times 10^{-4}$ & $2.58 \times 10^{-4} \pm 4.1 \times 10^{-6}$ & 103.0 \\
Sea water & $1.0 \times 10^{-6}$ & $1.02 \times 10^{-6} \pm 5.8 \times 10^{-8}$ & 102.0 \\
& $1.0 \times 10^{-5}$ & $1.04 \times 10^{-5} \pm 5.7 \times 10^{-7}$ & 104.0 \\
$9.5 \times 10^{-5}$ & $7.38 \times 10^{-5} \pm 2.8 \times 10^{-7}$ & 98.5 \\
& $1.0 \times 10^{-4}$ & $9.85 \times 10^{-5} \pm 4.9 \times 10^{-7}$ & 98.5 \\
& $2.5 \times 10^{-4}$ & $2.55 \times 10^{-4} \pm 2.6 \times 10^{-6}$ & 104.4 \\
\hline
\end{tabular}

\section{Conclusions}

In this study, a Pcv-modified GPE was used for electrocatalytic oxidation and FIA of sulfide for the first time. Comparison of the CVs of the Pcv/GPE with bare GPE show that the oxidation potential of sulfide shifted to more negative direction and peak current increased 2.5 fold in the case of CVs of the Pcv/GPE. These results have been showed that Pcv/ GPE exhibits the typical electrocatalytic properties of a modified electrode. Although Pcv has been used an efficient organic redox mediator for electrocatalytic oxidation of various compounds, it has not been used for electrocatalytic determination of sulfide in a FIA system. The proposed FI amperometric sensor has a wide linear range between 0.25 and $250 \mu \mathrm{M}$ with a detection limit of $0.07 \mu \mathrm{M}$. In addition, the applicability of proposed sensor to detection of sulfide in water samples was tested with a good accuracy. It can be concluded that the use of a Pcv/GPE in a FIA system exhibits a cheap, disposable, sensitive and rapid electrochemical approach for sulfide detection.

\section{Acknowledgement}

We thank the Scientific and Technological Research Council of Turkey (TÜBİTAK) for financial support (Project number: 115Z235). This study was conducted as part of that project and the MSc dissertation of Gamze Emir.

\section{References}

[1] A.B. Florou, M.I. Prodromidis, M.I. Karayannis, S.M. Tzouwara-Karayanni, Talanta, 2000, 52(3), 465-472.
[2] X. Cao, J. Gao, Y. Ye, P. Wang, S. Ding, Y. Ye, H. Sun, Electroanalysis, 2016, 28(1), 140-144.

[3] L.Y. Hu, S.L. Hu, J. Wu, Y.H. Li, J.L Zheng, Z.J. Wei, J. Liu, H.L. Wang, Y.S. Liu, H. Zhang, J Agr Food Chem, 2012, 60(35), 8684-8693.

[4] S.P. Li, K.D. Hu, L.Y. Hu, Y.H. Li, A.M. Jiang, F. Xiao, Y. Han, Y.S. Liu, H. Zhang, J Agr Food Chem, 2014, 62(5), 1119-1129.

[5] K. Cheng, K. Ueno, T. Imamura, Handbook of Organic Analytical Reagents, Second ed., CRC Press, Boca Raton, FL, 1992.

[6] Z.H. Xue, X.X. Fu, H.H. Rao, M.H. Ibrahim, L. Xiong, X.H. Liu, X.Q. Lu, Talanta, 2017, 174, 667-672.

[7] I.M. Steinberg, A. Lobnik, O.S. Wolfbeis, Sens Actuators B, 2003, 90(1-3), 230-235.

[8] A. Hennig, A. Hoffmann, H. Borcherding, T. Thiele, U. Schedler, U. Resch-Genger, Anal Chem, 2011, 83(12), 4970-4974.

[9] J. Zhu, X.Y. Wu, D. Shan, P.X. Yuan, X.J. Zhang, Talanta, 2014, 130, 96-102.

[10] S.Y. Deng, G.Y. Zhang, D. Shan, Y.H. Liu, K. Wang, X.J. Zhang, Electrochim Acta, 2015, 155, 78-84.

[11] M.A. Chamjangali, H. Kouhestani, F. Masdarolomoor, H. Daneshinejad, Sens Actuators B, 2015, 216, 384-393.

[12] Y. Wang, Colloids Surf B, 2011, 88(2), 614-621.

[13] S.M. Golabi, H.R. Zare, M. Hamzehloo, Electroanalysis, 2002, 14(9), 611-618.

[14] S. Ayaz, Y. Dilgin, Electrochim Acta, 2017, 258, 10861095.

[15] J. Zhu, D.S. Chauhan, D. Shan, X.Y. Wu, G.Y. Zhang, X.J. Zhang, Microchim Acta, 2014, 181(7-8), 813-820.

[16] S.M. Golabi, H.R. Zare, M. Hamzehloo, Microchem J, 2001, 69(2), 13-23.

[17] Q.L. Sheng, Y. Shen, J.B. Zheng, H.F. Zhang, Sens Lett, 2012, 10(3-4), 1007-1011.

[18] B. Fang, N. Zhang, W. Zhang, A. Gu, G.F. Wang, J Appl Polym Sci, 2009, 112(6), 3488-3493.

[19] Q. Sheng, H. Yu, J. Zheng, Electrochim Acta, 2007, 52(25), 7300-7306. 
[20] M.R. Nateghi, A. Bagheri, A. Massoumi, M.H. Kazemeini, Synth Met, 1998, 96(3), 209-212.

[21] G. Chen, S. Bi, L. Dai, M. Cao, Y. Chen, X. Wang, Anal Lett, 1999, 32, 865-883.

[22] N.S. Lawrence, J. Davis, R.G. Compton, Talanta, 2000, 52(5), 771-784.

[23] Y. Dilgin, B. Kızılkaya, B. Ertek, F. Işık, D.G. Dilgin, Sens Actuators B, 2012, 171, 223-229.

[24] Y. Dilgin, B. Kızılkaya, B. Ertek, N. Eren, D.G. Dilgin, Talanta, 2012, 89, 490-495.

[25] G. Emir, Y. Dilgin, Anal Lett, 2018, 51(1-2), 133-150.

[26] D.L. Vu, L. Cervenka, Electroanalysis, 2013, 8(25), 1967-1973.

[27] B. Ertek, D.L. Vu, L. Cervenka, Y. Dilgin, Anal Sci, 2012, 28(11), 1075-1080.

[28] Y. Dilgin, S. Canarslan, O. Ayyildiz, B. Ertek, G. Nişli, Electrochim Acta, 2012, 66, 173-179.

[29] J.L. Chang, G.T. Wei, T.Y. Chen, J.M. Zen, Electroanalysis, 2013, 25(4), 845-849.

[30] D.M. Tsai, A.S. Kumar, J.M. Zen, Anal Chim Acta, 2006, 556(1), 145-150.

[31] G. Roman, A.C. Pappas, D.K. Demertzi, M.I. Prodromidis, Anal Chim Acta, 2004, 523, 201-207.

[32] L.L. Paim, N.R. Stradiotto, Electrochim Acta, 2010, 55(13), 4144-4147.
[33] X. Cao, H. Xu, S. Ding, Y. Ye, X. Ge, L. Yu, Food Chem, 2016, 194, 1224-1229.

[34] P. Jeroschewski, C. Steuckart, M. Kühl, Anal Chem, 1996, 68(24), 4351-4357.

[35] E. Schmidt, A. Marton, J. Hlavay, Talanta, 1994, 41(7), 1219-1224.

[36] I.G. David, D.E. Popa, M. Buleandra, J Anal Method Chem, 2017, 2017.

[37] A.N. Kawde, N. Baig, M. Sajid, RSC Adv, 2016, 6(94), 91325-91340.

[38] J. Wang, A.N. Kawde, E. Sahlin, Analyst, 2000, 125(1), 5-7.

[39] Z.O. Uygun, Y. Dilgin, Sens Actuat B, 2013, 188, 78-84.

[40] S. Karakaya, Y. Dilgin, Electroanalysis, 2017, 29(6), 1626-1634.

[41] Ö. Sağlam, B. Kızılkaya, H. Uysal, Y. Dilgin, Talanta, 2016, 147, 315-321.

[42] B. Ertek, C. Akgül, Y. Dilgin, $R S C A d v$, 2016, 6, 20058 -20066 .

[43] A. Özcan, S. İlkbaş, Sens Actuat B, 2015, 215, 518-524.

[44] N. Jadon, R. Jain, A. Pandey, J Electroanal Chem, 2017, 788, 7-13.

[45] D.B. Kayan, D. Koçak, M. Ilhan, A. Koca, Int. J. Hydrogen Energy, 2017, 42(4), 2457-2463. 